\title{
ESCRITORAS MARGINALIZADAS
}

\author{
Carlos Magno Santos Gomes*
}

Resumo: Este ensaio apresenta um estudo sobre a importância do resgate de escritoras marginalizadas pelo cânone para a história das Literaturas de Língua Portuguesa, destacando a importância da inserção de Judith Teixeira e Alina Paim. Essas escritoras foram atuantes no campo literário, mas esquecidas pela censura de governos ditatoriais. Metodologicamente, faz-se uma abordagem historiográfica sobre a autoria feminina a partir dos estudos de Maria Lúcia Dal Farra, Elódia Xavier e Zahidé Muzart.

Palavras-chave: Historiografia; Judith Teixeira; Alina Paim.

Abstract: This work presents a study about the importance of rescuing writers marginalized by canon for the history of literature in Portuguese language, emphasizing the importance of including in it Judith Teixeira and Alina Paim. These writers were active in the literary field, but forgotten by dictatorial governments' censorship. Methodologically, it is historiographical approach about the female authorship from the studies by Maria Lúcia Dal Farra, Elodia Xavier and Zahidé Muzart.

Keywords: Historiography; Judith Teixeira; Alina Paim.

Na história das literaturas portuguesa e brasileira, diversas artistas foram invisibilizadas após deixarem de produzir. Entre as esquecidas, até bem pouco tempo, estavam Nísia Floresta, Júlia Lopes de Almeida, Judith Teixeira e Alina Paim. As primeiras já

* Universidade Federal de Sergipe. 
foram reinseridas nos estudos literários pelos diversos trabalhos acadêmicos sobre suas obras. Todavia, as duas últimas ainda são pouco conhecidas, mesmo no mundo acadêmico. Nessa direção, a historiografia de autoria feminina tem se tornado uma forma de resgate e de intervenção no cânone por meio de um "trabalho árduo e extenso do feminismo histórico, um movimento que tem uma ressonância política" (MUZART, 2011, p. 17).

A partir dessa estratégia, propomos uma reflexão sobre a importância do resgate e da inserção das escritoras marginalizadas na pauta dos estudos literários atuais. Para tanto, dividimos este artigo em dois momentos. No primeiro, ressaltamos a valorização da historiografia como um método de resgate relevante. No segundo, traçamos um roteiro de revisão da obra de Judith Teixeira e Alina Paim a partir da proposta feminista de suas obras. Teixeira, pela coragem com que rompe com o moralismo da sociedade portuguesa modernista ao descrever o amor homoerótico; Paim, pela força com que retrata a luta por liberdade das mulheres na sociedade patriarcal.

Em comum, a história das duas escritoras foi podada pela censura de governos ditatoriais. Para a construção de nossa tese, ressaltamos uma abordagem histórica que valoriza as particularidades estéticas e os desafios enfrentados por tais escritoras em seus respectivos contextos sociais. Metodologicamente, ressaltamos os estudos de Maria Lúcia Dal Farra, sobre a obra de Judith Teixeira, e a proposta feminista de Elódia Xavier, de inserção da obra de Alina Paim na história da literatura brasileira.

Com isso, valorizamos as questões ideológicas do texto literário. Essa estratégia nos possibilita "uma avalanche de reflexões sobre o campo literário e seus contextos culturais e institucionais" e, de modo especial, a mudança dos modelos e paradigmas referentes à "tradição, texto, leitura, gosto e valor" (SCHMIDT, 2010, p. 175). Nesse sentido, é possível deslocarmos o valor estético de lugar, pois a concepção do que seja literatura passa pelo reconhecimento das especificidades artísticas das escritoras em estudo. 
Entre os campos teóricos que assumiram a revisão do cânone, destacamos a importância dos Estudos de Gênero para a consolidação do trabalho de resgate das escritoras silenciadas. Essa historiografia é fundamental para a redimensão dos estudos literários de Língua Portuguesa. Tal trabalho procura organizar uma história e examina "como tais narrativas foram lidas pela crítica consagrada, como se encaixam nas correntes de sua época e como estabelecem relações com a literatura de seu tempo" (MUZART, 2011, p. 22). Dessa forma, o trabalho arqueológico possibilita a descoberta de escritoras que foram silenciadas por sua época e as reinserem nas historiografias atuais.

Levando em conta tais premissas, a historiografia das escritoras tem cumprido seu papel de resgate de artistas invisibilizadas "em consequência da utilização do gênero como uma categoria de análise" (CAMPELLO, 2010, p. 44). A atualização das historiografias nos movimenta na direção das releituras de obras esquecidas. Tal postura arqueológica é fundamental para a renovação dos estudos literários, pois leva em conta "a construção de uma consciência ética coletiva para a qual os saberes sobre as diferenças enquanto diferenças precisam convergir" (SCHMIDT, 2010, p. 184).

Dentro das possibilidades historiográficas, destacamos os manuais temáticos, os dicionários e as antologias. Entre elas, temos o levantamento histórico feito pelas pesquisadoras Conceição Flores, Constância Lima Duarte e Zenóbia Moreira com mais de dois mil verbetes que integram o Dicionário de escritoras portuguesas (2009). No Brasil, Zahidé Lupinacci Muzart organizou uma obra pioneira sobre a história de mulheres esquecidas Escritoras brasileiras do século XIX (1999). Esses exemplos comprovam que a produção de diferentes historiografias faz parte das estratégias para a construção de um novo olhar para a história das Literaturas de Língua Portuguesa.

Quanto aos resultados desse resgate, destacamos o fato de algumas escritoras, que ficaram fora da história literária, não serem envolvidas apenas com as subjetividades da literatura, 
pois, pelo contrário, são feministas engajadas com a luta das mulheres. Silenciadas pelas normas do campo literário de suas épocas, muitas delas apresentam a consciência da literatura como profissão, como os trabalhos pioneiros de Nísia Floresta, Maria Benetida Bormann e Inês Sabino, no século XIX (MUZART, 2011, p. 25). Mesmo com a modernização e ampliação do campo cultural e do entretenimento, ainda no século XX, há diversos exemplos de escritoras que permanecem invisibilizadas pela historiografia oficial.

O caso do esquecimento de Judith Teixeira é impressionante e assustador, pois revela o quanto o campo literário é controlado pelas regras do mercado editorial e pela concepção estética da moda. Contemporânea de Florbela Espanca e Fernando Pessoa, essa portuguesa foi uma pioneira na representação da homoafetividade feminina, pois incorporou as propostas futuristas de liberdade sexual para a mulher ao modelo de poesia modernista. Com isso, sua obra "escandalizou em razão do modo explícito e desassombrado como a autora fala do amor e do erotismo entre mulheres" (FLORES; DUARTE; MOREIRA, 2009, p. 148).

Vítima da invisibilidade imposta pelo governo militar brasileiro, Alina Paim também foi esquecida pela história da literatura logo após o golpe de 1964. Sua obra, marcada pelo realismo socialista e pela luta pelos direitos da mulher, não foi reconhecida pelas gerações seguintes. Todavia, seu engajamento socialista se confunde com seu projeto artístico. Seu romance Sol do meio-dia (1960), prefaciado por Jorge Amado, conquistou o primeiro prêmio do concurso da $\mathrm{ABL}$ (Associação Brasileira do Livro). Além disso, esse romance foi traduzido, por sua afinidade política com os países da cortina de ferro, para o russo, búlgaro e alemão. Em seguida, passamos a uma pequena história crítica das duas escritoras em destaque. 


\section{A marginalização de Judith Teixeira}

Judith Teixeira tem forte influência do "Manifesto Futurista da Luxúria", de Valentine de Saint-Point, lido e divulgado em Portugal, em 1917, por Almada Negreiros e Santa Rita Pintor (MARTINS, 2008, p. 845-846). Ao fazer opção por esse erotismo, Teixeira assume dupla marginalidade na história da literatura portuguesa: por ser mulher poeta e por ter uma "projeção lésbica". Ora, ao se colocar "numa terra de ninguém, numa posição indefesa perante uma moral burguesa, misógina e sexista que inundou a crítica e a literatura da época" (GIAVARA, 2012, p. 87), ela fica à mercê do julgamento da sociedade conservadora.

Em particular, Judith Teixeira provocou a tradicional sociedade portuguesa ao incorporar, de forma radical, as propostas transgressoras do Futurismo, elegendo o homoerotismo feminino como um de seus temas favoritos. Muitos estudiosos destacam tal postura como uma marca de sua poesia que traz "o direito feminino à Luxúria como expressão de sinceridade artística" (DAL FARRA, 2011, p. 299). Esse compromisso com os direitos sexuais das mulheres não foi aceito pelos valores sociais de seu contexto histórico.

Nascida em Viseu, em 1880, Judith Teixeira morreu no mais completo anonimato em 1959. Em 1913, é acusada de adultério e abandono do lar, quando dissolveu seu primeiro casamento. Em 1914, casou-se com o rico advogado e industrial, Álvaro Virgílio de Franco Teixeira. Em 1923, lançou a polêmica obra Decadência, que, por ressaltar o amor lesbiano, rendeu-lhe o apodo de "desavergonhada" (GIAVARA, 2012, p. 86).

Ela faz parte de um contexto histórico muito conturbado de Portugal. Em 1923, quando publica Decadência, sofreu um duro golpe quando teve suas obras destruídas e queimadas em praça pública. Esse repúdio aconteceu por suas obras fazerem referências ao homossexualismo feminino. Especificamente, foram desaprovadas pela Liga de Acção dos Estudantes de Lisboa (LEAL) que considerou tais textos imorais por afrontarem as virtudes da família portuguesa. 
Essa obra se mostra oposta às normas vigentes, pois se trata de um amor livre entre mulheres. Nesse mesmo ano, Judith Teixeira publicou Castelo de sombras, obra com menos destaque para o erotismo feminino. Em maio de 1926, ela voltou a lançar outro livro polêmico: Nua: poemas de Bizâncio, que foi recebido com críticas e paródias, por retomar o homoerotismo de forma revolucionária. Ainda nesse ano, publicou o texto memorialista De mim - Conferência em que explica suas concepções sobre a Vida, a Estética e a Moral. Em 1927, lança sua última obra Satânia: novelas.

Entre suas obras, Decadência foi que a mais incomodou os bons costumes portugueses por sua concepção vanguardista da descrição da luxúria. Além disso, seus poemas fazem referências aos conceitos de inconsciente descobertos por Freud. Entre os poemas que trazem a valorização da libido feminina, destaca-se "A estátua", pela forma sensual que descreve a silueta da mulher: "O teu corpo branco e esguio" (TEIXEIRA, 1996, p. 25). Nele, o corpo feminino é um tormento físico e espiritual para o eu lírico que se perde na visão dos "seios de bicos acerados" (TEIXEIRA, 1996, p. 25). Esse poema reforça a ideia do espaço homoafetivo como um lugar de liberdade sexual para os desejos femininos, pois ela incorpora as descobertas de Freud "sobre o poder da libido e sua influência no comportamento humano” (GIAVARA, 2012, p. 88).

Nesse sentido, a história literária tem sido muito injusta ao deixar de lado as obras dessa escritora que questionou as normas vigentes a partir de um fazer artístico vanguardista. Com esse propósito, a luxúria do desejo feminino irá se repetir em muitos outros poemas de Decadência, que também registra o preconceito que esse amor sofria. Em "A minha amante", há algumas pistas do quanto a sociedade se mantinha vigilante e controladora quando se tratava de uma relação homoerótica entre mulheres: "Dizem que eu tenho amores contigo!/Deixa-os dizer!.../Eles sabem lá o que há de sublime,/nos meus sonhos de prazer..." (TEIXEIRA, 1996, p. 62-63). 
Nesse poema, o modo como a sociedade vigia o amor da jovem por uma mulher mais experiente ressalta que o amor homoafetivo só é possível no espaço privado. Mesmo destacando que é vigiado, o eu lírico feminino ressalta seu direito à liberdade de viver aquele amor proibido, que não consegue esconder de ninguém. Apesar de pregar a liberdade, ainda se trata da representação de um amor só possível em um espaço privado. Portanto, sua obra choca ao motivar um novo olhar para esse amor, sem esquecer os limites dessa homoafetividade.

Além de ressaltar um amor lésbico, o poema "A minha amante" se destaca por contextualizar a sociedade conservadora da época. O deslocamento sexual da mulher é duplo, visto que se desloca para dentro de si para viver um amor proibido e precisa se isolar socialmente para ter acesso ao corpo da amada. Nesse caso, o amor do eu lírico feminino passa por um processo de aprendizado sexual ao confirmar seu interesse por outra mulher. Para além dessa abordagem sexual de sua obra, a crítica literária tem avançado ao reconhecer que Judith Teixeira tem uma veia artista portadora "de uma duplicidade que inquieta os sentidos, a ponto de alterar a Verdade, apenas para imprimir, à fantasia, a máxima expressão de realidade" (DAL FARRA, 2011, p. 282).

Atenta ao universo social, em "A minha amante", a poeta também descreve os problemas enfrentados por uma jovem que assumiu um amor lésbico ao detalhar as humilhações por que ela passa: "Levo risos de louca, no olhar!", porque sua atração pela amada é própria de um "ser destrambelhado e sensual!", de um "gênio do mal" (TEIXEIRA, 1996, p. 62-63). Tais atribuições à amada mais experiente deixam pistas do quanto, para a sociedade portuguesa, o amor lésbico era visto como fruto de uma mente doentia e pervertida.

Tal temática pode ser vista como inaugural nas Literaturas de Língua Portuguesa por valorizar o direto da liberdade sexual da mulher. Além disso, destacamos sua sensibilidade em construir um contexto social conservador em meio aos sonhos 
de mulheres ruborizadas pelo desejo homoafetivo. Assim, ao descrever o julgamento social sofrido por esse amor, a escritora portuguesa traz para o texto literário as tensões sociais referentes à normatização sexual, quando reconhece que o amor entre duas mulheres é visto como uma "tara perversa", própria do "gênio do mal", conforme Judith Teixeira ressalta no poema "A minha amante" (TEIXEIRA, 1996, p. 62-63).

Assim, constatamos que sua postura ideológica é de questionamento, ao contextualizar problemas referentes à liberdade das mulheres, pois "em seus textos, o prazer é associado irremediavelmente à dor e ao pecado, na intuição de um eros tingido de sadomasoquismo" (SILVA; VILELA, 2011, p. 75). Mas o papel desbravador dessa escritora não se limita às suas obras. Ela também foi responsável pela divulgação da arte moderna em Portugal a partir de 1925, quando se tornar editora da revista magazine Europa. Ao assumir essa posição, Judith Teixeira torna-se uma mulher intelectual à frente de sua época, publicando tanto os novos, quanto os conhecidos escritores modernistas como "Florbela Espanca, Almada Negreiros, Amadeo de Souza Cardoso, Milly Possoz, Américo Durão, Ferreira de Castro" (DAL FARRA, 2011, p. 313).

A invisibilidade dessa escritora pode ser vista como uma estratégia canônica da literatura portuguesa de só reconhecer escritores que respaldam os valores conservadores de uma sociedade preconceituosa. Suas representações homoeróticas foram rejeitadas pela sociedade de sua época e banida da história oficial por muitas décadas. Portanto, a posição pioneira de Judith Teixeira vai além do estilo vanguardista da representação do amor entre mulheres, visto que repudia o conservadorismo do modernismo português, ao optar por um "discurso sáfico do homoerotismo" (SILVA; VILELA, 2011, p. 73). 


\section{O engajamento feminista de Alina Paim}

Alina Paim foi uma escritora engajada com a luta dos oprimidos e uma militante do PCB. Nasceu em 10 de outubro de 1919, na cidade de Estância, em Sergipe. Depois de uma agitada vida política no Rio de Janeiro, ficou invisibilizada durante a Ditadura Militar e passou os últimos anos de vida, em Mato Grosso, na companhia de uma filha até primeiro de março de 2011.

Marcada por uma literatura de cunho socialista, Alina Paim foi uma escritora preocupada com denúncias, questionamentos e luta de classes. Seus romances relatam "o despotismo dos fortes sobre os fracos, o amor como caminho de realização ou de destruição dos seres humanos, a desumanidade do sistema de exploração da força-trabalho, que caracteriza a sociedade brasileira em geral" (COELHO, 2002, p. 39).

Entre suas principais obras, destacam-se seus romances: Estrada da liberdade (1944); Simão Dias (1949); A sombra do patriarca (1950); A bora próxima (1955); Sol do meio-dia (1961); a trilogia de Catarina composta pelos romances: $O$ sino e a rosa (1965); A chave do mundo (1965) e O círculo (1965); A correnteza (1979); A sétima vez (1994). Além dessa produção, Paim publicou livros infantojuvenis e diversos artigos em periódicos no Rio de Janeiro, Salvador e Aracaju, cidades onde mantinha amigos e partidários das causas políticas.

Alina Paim tem importante participação na vida literária e política do Brasil, todavia é uma voz silenciada nos manuais historiográficos. Amiga de Graciliano Ramos e Jorge Amado, com dez romances publicados entre 1944 e 1994, ela foi deixada de lado na maioria dos livros de história literária apesar de ter uma obra com duas abordagens: o de grande teor social, característico de seu engajamento político e partidário; e o da introspecção, marca dos romances da maturidade dos anos 60 (CARDOSO, 2010, p.125). 
Elódia Xavier ressalta essa preocupação introspectiva em sua literatura, sobretudo na trilogia de Catarina, que descreve o universo psicológico da mulher e seus desafios diante do patriarcado. Em tais obras, há uma aproximação entre ficção e história da própria escritora, pois "nos faz pensar numa narrativa de natureza autobiográfica, dada a intimidade entre narrador e protagonista" (XAVIER, 2009, p. 72). Tal aproximação entre vida e obra desta autora é possível por não ter uma preocupação em diferenciar os fatos biográficos dos ficcionais, visto que sua "história de vida confunde-se com aquela das suas personagens, quase sempre enredadas num espaço familiar conflituoso ou no interior de algum convento" (CARDOSO, 2010, p.125).

Além dessa particularidade, sua ficção é composta de "sutilezas semânticas, que exigem do leitor uma atenção redobrada para que o sentido não se perca" (XAVIER, 2009, p. 77). Com esse elaborado texto de sutilezas e lutas, a obra de Alina Paim se destaca pela representação dos excluídos e da luta dos direitos da mulher. Nessa perspectiva, é possível afirmar que a mulher está no centro de sua literatura, visto que o discurso feminista sempre entrecorta as falas de suas personagens sedentas por justiça e igualdade de direitos tanto no cotidiano da família patriarcal como no espaço do trabalho. Com isso, sua obra tem uma relação com o modernismo realista e está "profundamente sintonizada com as forças transformadoras do nosso tempo" (COELHO, 2002, p. 39).

Na perspectiva histórica, Alina Paim faz parte das escritoras preocupadas com o romance de formação, visto que a liberdade de suas personagens é uma marca de sua ficção. Na trilogia de Catarina, a formação da mulher está em jogo de sua infância à fase adulta, portanto trata-se de um romance de formação, um Bildungsroman feminino. Nessa obra, depois de muitos desafios, Catarina, a protagonista dos três romances, faz uma escolha pessoal e pode ser vista "como um corpo liberado, pois quando se tem a chave do mundo, tem-se a liberdade de escolha de abrir a porta desejada. E esta liberdade vem respaldada pelo amadurecimento, pela longa e dura aprendizagem." (XAVIER, 2009, p. 78). 
Para melhor inseri-la na história literária, vamos retomar o processo de aprendizagem da mulher transgressora na obra $A$ sombra do patriarca (1950). Nossa proposta é mostrar que a protagonista, Raquel, faz parte das mulheres que romperam com as normas do engenho do Tio Ramiro para viver em liberdade. Nessa obra, Alina Paim apresenta um intrínseco diálogo com o realismo social ao incluir personagens pobres e marginalizados no engenho.

Com isso, seu romance vai além das representações tradicionais de mulheres burguesas em busca de uma formação interior. Nessa obra, Raquel, em sua trajetória pelas fazendas do tio Ramiro, apresenta uma postura politizada de luta pelos direitos da mulher. Além disso, trata-se de uma protagonista pobre que sonha em mudar o mundo, pensa na democracia e na igualdade dos direitos entre homens e mulheres.

Em $O$ bildungsroman feminino: quatro exemplos brasileiros (1991), Cristina Ferreira Pinto desenvolve uma proposta, por meio de uma perspectiva comparatista, de que o romance de formação feminino torna-se mais feminista à medida que apresenta protagonistas que não são punidas. Essa pesquisadora cita Joana, de Perto do coração selvagem (1944), de Clarice Lispector, e Virgínia, de Ciranda de pedra (1954), de Lygia Fagundes Telles como as primeiras personagens a romperem com o destino de mulher. Nessas obras, observamos que o ponto em comum é o fato de a protagonista abrir "mão de um determinado sentido de integração social para alcançar algo mais valioso e satisfatório - a integração do EU" (PINTO, 1990, p. 19). Fugir de famílias tradicionais, de maridos opressores e de casamentos falidos tem sido uma sina para mulheres transgressoras nos romances de formação feminina.

Em Declínio do patriarcado (1998), Elódia Xavier, em uma análise histórica, revela que o fracasso do patriarcado é um tema recorrente na ficção brasileira de autoria feminina. No romance de formação feminina, percebe-se claramente a 
recorrência da família como um espaço ambíguo, pois tanto é de manutenção como de questionamento da tradição, tratando-se de um "lugar de adestramento" e "responsável pelos conflitos narrados" (XAVIER, 1998, p. 13-14).

No romance de Alina Paim não é diferente: Raquel, ao transitar pelas fazendas de Tio Ramiro, depara-se com famílias tradicionais comandadas pelo patriarca. Esse personagem é descrito como um "Senhor feudal (...) um patriarca, domina a família inteira - os irmãos, esposa, os filhos, genros, netos, sobrinhos" (PAIM, 1950, p. 58). Em contrapartida, as mulheres que se envolvem com a educação são fortes. Elas lutam contra a imposição das normas e da tradição.

Desse modo, podemos deduzir que a ficção de Paim traz o descentramento da identidade feminina a partir de sua formação educacional. Em A sombra do patriarca, há diversas personagens que rompem com os padrões patriarcais após leituras de cunho socialista. Por exemplo, D. Gertrude incentiva leituras críticas e de formação diferentes daquelas que tinham na fazenda do Tio Ramiro. Ela indicava Tolstói, Ressurreição, "para lhe abrir as ideias" (PAIM, p. 49). Essa personagem é descrita como destemida, por não aceitar o adestramento imposto à mulher: "a revolta é como uma luz que de repente se acendesse nas trevas. Quem vê essa chama enxerga o caminho, não precisa mais de guia" (PAIM, 1950, p. 49-50).

Tal orientação é fundamental para a formação de Raquel que reconhece o quanto as leituras foram importantes para a formação de sua identidade transgressora: "Para mim tornou-se mais poderoso que qualquer livro conhecido até aquele momento" (PAIM, 1950, p. 11). Essa a protagonista não se dobra diante dessa tradição e rompe com os esquemas que lhe são impostos. Assim, como uma personagem transgressora, ela supera "as limitações sociais e atinge a independência e afirmação pessoal desejadas, assumindo uma posição marginal que é agora escolba, liberação" (PINTO, 1990, p. 149). 
Nesse sentido, a inclusão de Raquel na tradição das protagonistas transgressoras do romance de formação possibilita o vínculo de $A$ sombra do patriarca ao sistema literário brasileiro. Com isso, o resgate de Alina Paim pode ser visto também como uma nova abordagem histórica desse gênero literário, ampliando os espaços do romance feminino e as problemáticas de gênero por que passam suas personagens.

Dessa forma, uma das saídas para o resgate de escritoras marginalizadas é um estudo historiográfico de revisão, colocando as representações da escritora desconhecida em tensão com as já consagradas pelo cânone. No caso analisado aqui, a partir dessa perspectiva inclusiva, a literatura de Alina Paim pode ser valorizada pelas representações de mulheres emancipadas pela educação.

\section{Considerações finais}

Como visto, o resgate é uma das mais importantes formas de questionamento da história da literatura, pois amplia a coleção de textos que faz parte do patrimônio cultural de um país. Tanto Judith Teixeira, quanto Alina Paim não podem ficar de fora da historiografia das literaturas de língua portuguesa, visto que produziram obras que contestam os valores culturais de sua época. Entre outros aspectos próprios da historiografia de resgate, também reconhecemos que sua emergência é própria de uma articulação política que explora a estratégia feminista de "inserção das mulheres no cânone literário" (MUZART, 2011, p. 20).

Se Judith Teixeira foi silenciada pelo conservadorismo lusitano, Alina Paim foi menosprezada pela forma engajada de fazer literatura. As duas são exemplos das injustiças do cânone tradicional. Cabe destacar que a portuguesa é dona de uma poesia genial, questionadora das fronteiras sexuais e dos papeis sociais das mulheres na sociedade portuguesa. A brasileira tem uma relação de camaradagem com o romance realista brasileiro e precisa ser revisitada para ter a força de sua narrativa reconhecida como um episódio da luta da mulher brasileira por sua liberdade. 
Ora, as duas escritoras ficaram de fora da história da literatura por suas opções estéticas. Judith Teixeira foi atacada e criticada publicamente e somente há pouco tempo "voltou a despertar o interesse dos estudiosos da literatura e das editoras portuguesas." (FLORES; DUARTE; MOREIRA, 2009, p. 149). Do mesmo jeito, Alina Paim estava marginalizada pela história literária, pois "quase ninguém leu essas obras" de uma escritora "que só agora começa a ser resgatada da invisibilidade" (XAVIER, 2009 , p. 77). Duas artistas injustamente silenciadas por questões ideológicas.

Portanto, com o estudo das escritoras silenciadas por questões políticas, reconhece-se o relevante papel do resgate para se ampliar a história literária. A partir dessa valorização incondicional, "os estudos literários podem articular o seu papel educacional com uma função social de relevância", pois abrem "o campo de reflexão e crítica às formas de silenciamento e exploração do humano" (SCHMIDT, 2010, p. 184). Neste contexto, os estudos arqueológicos feministas são indispensáveis, pois elegem o "perfil feminino/feminista" como "elemento permanente na historiografia literária brasileira" (CAMPELLO, 2010, p. 48). 


\section{Referências}

CAMPELLO, E. Um novo perfil para a historiografia literária: escritoras brasileiras. In: SCHMIDT, R. T. (Org.) Sob o signo do presente: intervenções comparatistas. Porto Alegre: Ed. UFRGS, 2010, p. 43-54.

CARDOSO, A. M. L. Alina Paim - uma romancista esquecida nos labirintos do tempo. Aletria, Belo Horizonte, v. 20, n. 2, p.125-132, 2010.

COELHO, N. N. Dicionário crítico de escritoras brasileiras: 1971 - 2001. São Paulo: Escrituras, 2002.

DAL FARRA, M. L. O maldito no feminino: Gilka Machado e Judith Teixeira. In: SANTOS, J. ET AL. Sombras do mal na literatura. Maceió: EDUFAL, 2011. p. 277-304.

FLORES, C.; DUARTE, C.; MOREIRA, Z. Dicionário de escritoras portuguesas. Florianópolis: Mulheres, 2009.

GIAVARA, S. M. Muito prazer, Judith Teixeira! Miscelânea, Assis, v. 11, p. 81-94, 2012.

MARTINS, F. C. (Coord.) Dicionário de Fernando Pessoa e do modernismo português. Lisboa: Caminho, 2008. p. 845-846.

MUZART, Z. L. A ascensão das mulheres no romance. In: ALVES, A. ET AL. (Orgs.) A escritura no feminino: aproximações. Florianópolis: Mulheres, 2011. p. 17-27.

PAIM, A. A sombra do patriarca. Rio de Janeiro: Editora Globo, 1950.

PINTO, C. F. O bildungsroman feminino: quatro exemplos brasileiros. São Paulo: Perspectiva, 1990.

SCHMIDT, R. T. Centro e Margens: notas sobre a historiografia literária. In: DALCASTAGNÈ, R.; LEAL, V. (Orgs.) Deslocamentos de gênero na narrativa brasileira contemporânea. São Paulo: Horizonte, 2010, p. 174-187.

SILVA, F. M.; VILELA, A. L. Homo(lesbo)erotismo e literatura, no Ocidente e em Portugal: Safo e Judith Teixeira. Navegações, Porto Alegre, v. 4, n. 1, p. 69-76, 2011.

TEIXEIRA, J. Poemas. Lisboa: \& Etc, 1996.

XAVIER, E. Declínio do patriarcado. Rio de Janeiro: Rosa dos Tempos. 1998. 
XAVIER, E. Que corpo é esse?: o corpo no imaginário feminino. Florianópolis: Ed. Brasil, 2007.

XAVIER, E. A construção de um corpo liberado: a trilogia Catarina, de Alina Paim. Cadernos de Literatura Contemporânea, Brasília, v. 33, p. 71-80, 2009.

Recebido para publicação em 21 de dezembro de 2013 Aprovado em 02 de abril de 2014 